\title{
Study on the Planning and Design of the Residential Area Road under the Influence of "Block System"
}

\author{
Qian Liu ${ }^{1, \mathrm{a}}$, Guoqing $\mathrm{Li}^{1, \mathrm{~b}, *}$ and Xiaokang $\mathrm{Hu}^{2, \mathrm{c}}$ \\ ${ }^{1}$ School of Urban and Rural Planning,Agricultural University of Hebei,Hebei 071001,China. \\ ${ }^{2}$ China Architecture Design Group,Town Planning Research Institute,Beijing 100044,China. \\ a1452693069@qq.com, ${ }^{\mathrm{b}}$ 1728756457@qq.com, ${ }^{\mathrm{c}}$ 447160538@qq.com
}

Keywords: Block system, Residential area road status, Planning strategy

\begin{abstract}
The purpose of the promotion of the block system is to open the closed residential district and the unit yard, realize the internal road communalize and solve the problem of the layout of the road network. This will inevitably lead to a change of ideas in the design of residential district road, which will prompt us to rethink how the road system in the open residential area should be planned. This paper analyzes the existing problems in the domestic residential area road system and puts forward the planning strategy of open residential area road.
\end{abstract}

\section{Introduction}

At present, the residential areas of China are basically closed, and the internal and external traffic can not connect, so the roads in the residential areas cannot share the traffic pressure of urban roads. For the residential area itself, the period of concentration of vehicles is before and after work, and there are not many vehicles at other times, which leads to waste of resources. At the present stage of residential area road system exists many problems, and at this time the central government promotes "block system", which is a good opportunity to rethink how to plan the residential district road.

\section{Problems existing in the road system of domestic residential communities}

\subsection{Road traffic function is too onefold, non-motor vehicles are not valued}

The road of residential district belongs to life road, and the main service object of the traffic function of road space should is residents daily travel, but present the life-arena function of the internal road of the residential area is weakened gradually, and gradually evolved to simply meet the traffic demand function. The road space in residential areas is becoming more and more suitable for cars, and non-motor vehicle driving space is ignored, or even not. For example, the sidewalk is becoming narrower and narrower; a car takes up walking space.

2.2 The number of traffic accidents is increasing, and the lack of attention to the safety of special groups

With the increase of the number of motor vehicles, the number of traffic accidents caused by motor vehicles is increasing. Street traffic safety became a new problem in the city, and the internal traffic safety of the residential area is also greatly affected. Although some residential quarters have done some parts of the people's car shunt or the complete meaning of the people's car shunt, but some unreasonable design also creates safety hidden trouble. In comparison, the elderly and children in the residential area stay in the area longer, however, they have not received adequate attention, and there are no reasonable measures have been taken to reduce the risk of accidents. [1]

\subsection{The sense of space security weakened}

The modern determinant house is divided by front and rear lanes, the enclosure of space is destroyed, and the function of the place of life in the street is gradually weakened. The spatial scale based on the car as a benchmark to makes people feel uncomfortable, the sense of the space domain 
is lost, the attendant, people are no longer willing to stay in this space, communication activities reduced,so the decrease of people leads directly to the unsafe space produce. Such a spatial environment also increases the chances of a criminal incident. [1]

\section{Planning strategies for open residential areas road}

\subsection{Build an open residential area and build the proper block scale}

In the "Code of urban Residential Areas Planning \& Design",table 3.0.3 specifies the per capita residential land control index ( $\mathrm{m} 2$ / person), and selects the residential area data related to the topic. according to the Code specified 10000-15000 population scale of the residential area, selects the lowest population:10000 people,you can obtain residential area land use scale, such as Table 1.

Table 1. Residential Area Land Use Scale.

\begin{tabular}{|c|c|c|c|c|}
\hline Living scale & The layer number & \multicolumn{3}{|c|}{ Building climate zoning } \\
\cline { 3 - 5 } & & $\begin{array}{c}\text { I II、VI、 } \\
\text { VII }\end{array}$ & III V & IV \\
\hline \multirow{3}{*}{$\begin{array}{c}\text { Residential } \\
\text { area }\end{array}$} & Low-rise residential & $30 \sim 43$ ha & $28 \sim 40$ ha & $26 \sim 37$ ha \\
\cline { 2 - 5 } & Multi-storey residential & $20 \sim 28$ ha & $19 \sim 26$ ha & $18 \sim 25$ ha \\
\cline { 2 - 5 } & Mid-rise residential & $17 \sim 24$ ha & $15 \sim 22$ ha & $14 \sim 20$ ha \\
\cline { 2 - 5 } & High-rise residential & $10 \sim 15$ ha & $10 \sim 15$ ha & $10 \sim 15$ ha \\
\hline
\end{tabular}

According to a survey in the UK town of Stevenage, Respondents believe that with their own have the common neighborhood recognition and ownership only about 2000 people; Alexander also through the investigation and analysis pointed out that people's cognitive neighborhood diameter of not more than $274 \mathrm{~m}$, that is, the area of about $5 \mathrm{hm} 2$.Chinese scholars Zhou Jian and so on, through the sampling survey of Shanghai urban residential space, it is proposed that the size of residential quarters should be no more than $150 \mathrm{~m}$ of the spacial scale or $4 \mathrm{hm} 2$ of the land scale [2]. By comparing with the data on the table, we can see that the size of residential district in China is obviously too large, and the large plots plus the closed management of district lead to too large distance between urban roads, bring inconvenience for people to travel on foot,and make people become increasingly dependent on the way of car travel. Therefore, we should open the gate of gated communities, turn the large block into small block, and build an open residential district.

By summarizing the different scholars' research on the change characteristics of the street spacing in the urban center area, it is found that the most stable street spacing is about $100 \mathrm{~m}$; In urban development,the street spacing between $200-400 \mathrm{~m}$ (especially the $400 \mathrm{~m}$ ) is possible to be encrypted. In combination with the actual situation of China's road network structure, it is not suitable to set oversized street spacing in the planning of urban central area in the future,150-200m more appropriate. [3]

\subsection{Re-division of road grade in the residential area}

"Code of urban Residential Areas Planning \& Design"stipulates: the road in residential area is divided into residential area road, residential district grade road, group road, house road, residential area road is often equivalent to the city slip road, and combined with "Code for design of urban road engineering"(CJJ37-2012) discusses the redivision of the road grade of the open residential area. Residential area refers that the area is enclosed by urban arterial roads or natural boundaries, and correspond to the population scale of $30000-50000$ people; Land scale is $60-100 \mathrm{hm} 2$, its surround close road network spacing is 0.8-1.0 km.In that way,the residential area road constitutes the urban slip road,the group road constitutes a "neighborhood road", and the residential district level road becomes the secend level branch road,which connecting the "neighborhood road" and "the branch road". However, urban roads are public;in practice, residential district grade roads tend to limit cross-border traffic, and even closed management, which is essentially "block roads" (Fig1). [4] 

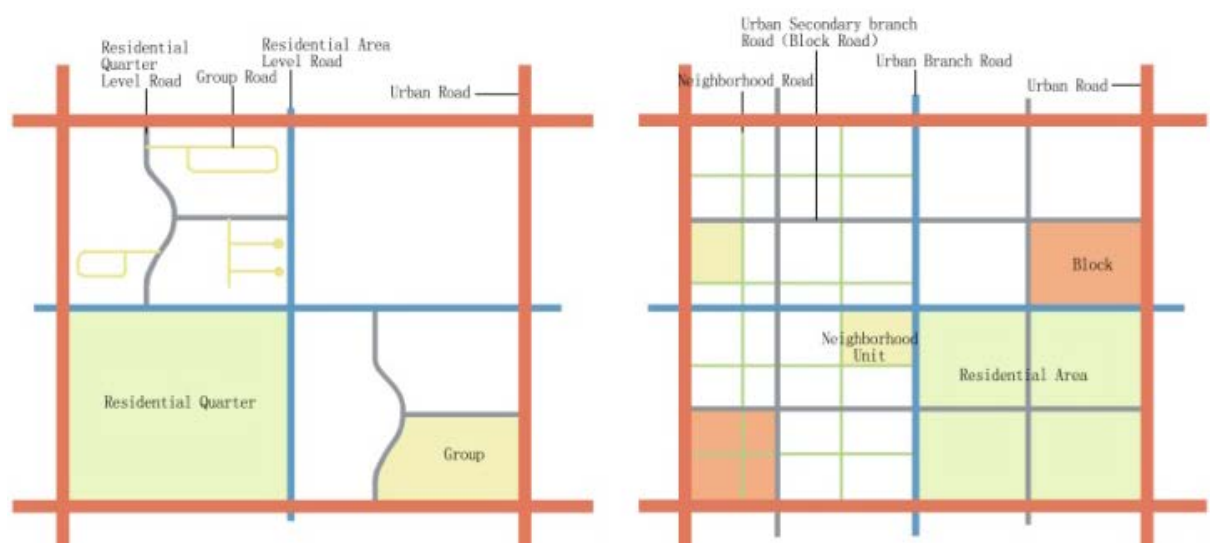

Fig 1. The traditional community pattern and the open area model road network

\subsection{The encryption of the residential road}

Based on the total travel time, without considering other modes of transportation, the optimal distance between pedestrians, bicycles and motor vehicles is respectively70-100m, 150-200m, $400-600 \mathrm{~m}$. In our country, the overall planning of the city is often used in the $(400-500 \mathrm{~m}) \mathrm{X}$ (400-500m) of the road network scale, it is difficult to meet these three kinds of traffic modes for the suitable running requirements,and ultimately chose to sacrifice the interests of walking and bicycle, to cater to the development of the car (Fig 2). In China at this stage of the road network model is 3, 4, these two models do not meet the norms of the density requirements of the branch road and the density requirements of road network, which belong to the large spacing road network. [4]

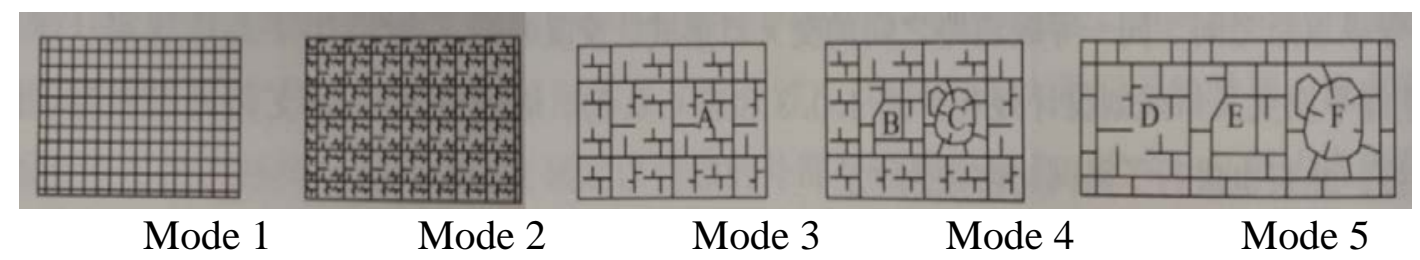

Mode 1:The walking suitable distance is $150-200 \mathrm{~m}$.

Mode 2:The bike suitable distance of $150-200 \mathrm{~m}$.

Mode 3 and Mode 4:Car suitable distance of 400-600m.

Mode 5:Automobile suitable distance of 700-1000m (long-distance travel)

Fig 2. Suitable road network mode for each mode of transportation

Therefore, by encrypting large spacing networks,it's formed urban living roads or pedestrian corridors. Traffic demand different regions can take different measures;such as for areas with relatively large traffic demand, can take measures of adding urban branch road, but should be restricted and controlled using of private cars excessively, as setting one-way line; and for areas where traffic demand is not too large, can take measures of increasing non motorized lines and pedestrian corridors(Fig 3).[5] 

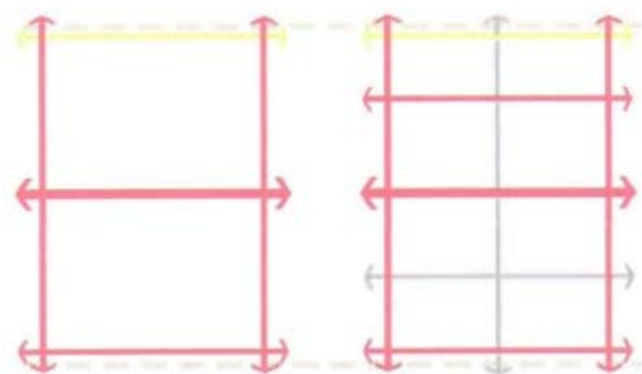

a:Large blocks

b:Add city branch

c:Add a non-motorized line

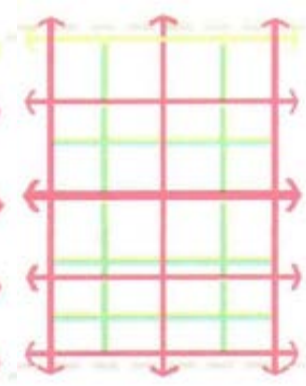

Fig 3.Large spacing road network encryption method

By encrypting the block road network, these roads are planned as a continuous and convenient network, not only can encourage and promote public transport, non-motorized traffic and walking traffic, making residential traffic and urban plaque better cohesion, but also can form the important place and space of residents' daily life , create a good residential environment.

\subsection{Create efficient and convenient transportation system}

\section{1) Urban public transport introduced into blocks, to create a "bus + slow" as the leading road} system

Domestic and foreign practice has proved that "bus + slow" dominated travel mode can better solve the problem of traffic congestion,to a certain extent, restrictions on car travel, will be more traffic space left to people, bicycles and public transport. [6]

To solve the current urban streets on both sides of the motor vehicle is often occupied by the problem,to achieve the city public transport really for the residents of travel services,it must be given public transport vehicles and facilities in urban land use priority.In addition, we should also take full consideration of the functional positioning of the streets, clear the use of the street section,and in the streets with large flow of people and small traffic flow,we can use the mode of "man car sharing" space; or the car more important streets, you need to use the way of separation of man and vehicle and human beings and non motorized vehicles,to ensure the friendly order of each function space.

\section{2) Pay attention to the connection between the bus system and the slow system}

Residential slow system and the bus system should be a reasonable cohesion,and shall ensure that people change to the process of efficient, convenient and comfortable, which requires the bus interchange layout reasonable, the service radius is suitable, and equipped with bicycle parking spots.

According to the Vanke Building Research Center's survey about from the Shenzhen Four Seasons Huacheng's residential groups to the bus station distance and residents feel shows that the distance from the slow to the bus station, below 750 meters is appropriate [7]. Therefore, the bus stop should be set in the city's secondary branch road (neighborhood road), which can be deep deep into residential area, can have close contact with the slow flow of people, to attract people into the bus transfer point, then bring the flow of people through the transfer site transfer into the urban transport network; and may be appropriate to increase the detour distance between the bus lines, so that both the reduction of public transport vehicles and other social vehicles interfere with each other, but also provide a safe travel conditions for the residents, and expand the bus service area and reduce the average slow traffic distance of the residents. In addition, the comfort level of the slow lane affects people's psychological feelings about far or near of the slow traffic distance.

Also, pay attention to the relationship between bus stops and bike parking spots. The suitable distance between the bicycle stop and the bus stop is about $100 \mathrm{~m}$, walk for 2 minutes and avoid the road intersection and main road. [8] 


\section{3) Create a safe and comfortable slow environment}

(1) Create a secure slow environment

The introduction of bus and slow traffic to the residential blocks is bound to have a certain impact on residents' life. Therefore, relevant measures should be taken in the road system to reduce the impact of high-speed motor vehicle traffic on local residents.

"Traffic tranquility" design method has been mature in foreign countries, and has been widely used, but in China has applied less."Traffic tranquility" is to reduce the speed by means of raised pavement, raised pavement, narrow lane, narrow junction and so on(Fig 4), fully to protect the slow priority, to provide a comfortable and safe walking environment for pedestrians,to provide continuous smooth flow of traffic space for bicycle,to promote the use of the street of people.

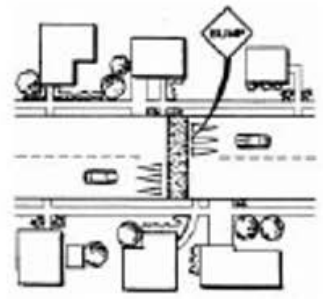

a. Raised pavement

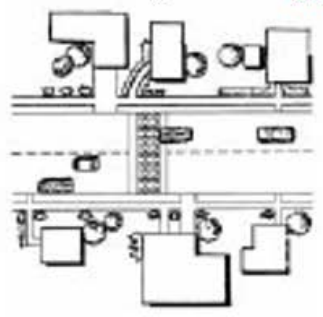

b. Raised sidewalk

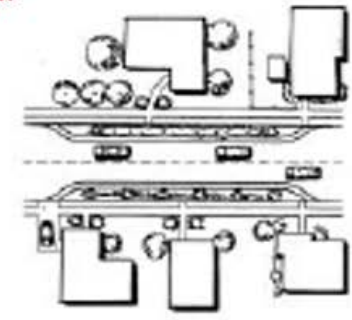

c. Lane narrowing

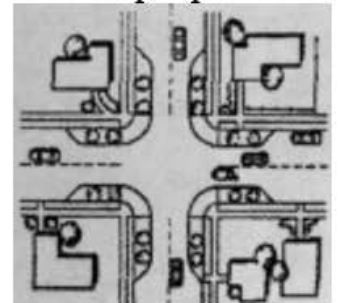

d. Crossroads narrow

Fig 4: Traffic safety measures

(2) Create a comfortable and open slow traffic space

Comfortable, open, fun, human-friendly slow traffic space will attract people to stop and stay, thereby increasing popularity and communication, promoting the growth of walking or cycling.

The establishment of the slow traffic space should began from the courtyard inside the block , through the walking corridor, connecting the public space on both sides of street ,which is generated due to the building retreat or building enclosures, as well as blocks parks, urban greenway, forming point-line-surface structure, thus forming a continuous slow traffic space. Slow space nodes to adapt to the natural environment, and the conscious use of some emotional symbols, according to the slow sequence of people, the atmosphere of the atmosphere rendering, to mobilize people's emotions, people in the process of walking constantly feel To the pleasure, while avoiding the existence of insecure factors in the negative space. In addition, we should pay attention to the design of human nature such as landscape scale and street rest area, and fully consider the use requirements of different groups.

\section{Conclusion}

With the continuous development of our society, block system is an inevitable result. Only change residential road planning and design ideas, can make residential roads and urban road better cohesion, form a reasonable urban traffic network, and solve the problem of urban traffic, to make the residential better adapt to the rapid development of the city.

\section{References}

[1] Yang Yang, The safety study of road design in residential area based on two examples, Beijing Forestry University, 2010.

[2] Lechun Wang, Research on Urban Residential Block Model, Hunan University, 2010.

[3] Hui Sun, Jiang Liang, Mode and Motivation: Morphological Evolution of Urban Center of China, China Architecture \& Building Press, 2007.

[4] Jun Cai, Urban Road Network System Planning, China Architecture \& Building Press, 2013. 
[5] Xiaohan Cai, Research on Planning and Design of Residential Blocks Under the Urban Grid Traffic Initiative, Shandong Jianzhu University, 2014.

[6] Xuejiao Chen, "Way" to "Street" Concept - Dynamic Blocks Under Construction to Incorporate Traffic Space and Public Space Research for Old Area Revitalization of, The Academic Committee of the Urban Planning Society of China Urban Traffic Planning. In 2016 China's Urban Traffic Planning Conference, Proceedings of the Urban Planning Society of China Urban Traffic Planning Academic Committee:,2016:16.

[7] Jing Yang, Jin Ma. Planning and Design of Residential Areas with Urban Iinteraction, Southeast University Press, 2008.

[8] Xiaonan Zhao. Construction of Slow System Construction in Urban Residential Areas, Harbin Institute of Technology, 2010. 